\title{
The effect of age on normal values of the Westergren sedimentation rate
}

\author{
F. M. HILDER AND F. W. GUNZ \\ From the Department of Pathology, Christchurch Hospital, Christchurch, New Zealand
}

SYNOPSIS Westergren sedimentation rates were done on 603 healthy blood donors. The results showed an increase in the normal values with age. The normal values found in this series were higher than those generally accepted as normal.

The commonly accepted normal values for the Westergren method of determining the sedimentation rate (E.S.R.) are $3-5 \mathrm{~mm}$. in the first hour for males and 7-12 mm. for females (Whitby and Britton, 1963). During routine blood testing we found a number of apparently normal persons whose E.S.R. exceeded these ranges, and in order to assess the significance of this finding, we undertook a survey of the E.S.R. in healthy blood donors. The results showed that the normal E.S.R. is dependent on age as well as sex.

\section{METHODS}

We used Dawson's (1960) modification of the original Westergren method. Its essential feature is that the sedimentation tubes are suspended instead of being supported in a vertical position; errors due to deviation from the vertical are thereby automatically avoided.

As a preliminary check on the reproducibility of results the E.S.R. was determined by Dawson's method six times at weekly intervals on the venous blood of five male and five female laboratory workers (60 determinations). The values ranged from 1 to $11 \mathrm{~mm}$. per hour, and the total variation in any one individual did not exceed $3 \mathrm{~mm}$. per hour.

Blood for the E.S.R. determinations was obtained from donors immediately after 400 to $420 \mathrm{ml}$. of blood had Received for publication 12 September 1963. been withdrawn by a vacuum method. Through the intra-음 venous set which had been used for the donation $\mathrm{a}^{-}$ further $5 \mathrm{ml}$. of blood was aspirated into an evacuated $5 \mathrm{ml}$. bijou bottle containing $5 \mathrm{mg}$. of sequestreneर (E.D.T.A.). The bijou bottles were left standing at room temperature for one to three hours and then mixed on aD rotary mixer for a minimum of two minutes. Exactly $2 \mathrm{ml}$. of blood from each sample was then mixed in another bottle with exactly $0.5 \mathrm{ml}$. of $3.8 \%$ sodium citrates solution, the same rotary mixer being again used for at least two minutes. One standard Westergren pipette waš filled from each sample by drawing blood above the zerod mark and allowing it to run back to avoid the reflux effect (Alexander, 1953). The tubes were suspended foro흠 one hour and read, the reading being corrected for temperature (Manley, 1957). Room temperatures varied from 20 to $24^{\circ} \mathrm{C}$.

\section{RESULTS}

A total of 603 unselected blood donors was tested in two series. The first consisted of 182 males and 114 females. These were divided into five age groups 0 $18-30,31-40,41-50,51-60$, and over 60 years. The mean value and standard deviation were calculated for each age group and showed a steady increase with age. In order to check this result a second series of 213 males and 94 females was tested, and similar figures were obtained for the means and standarct

TABLE I

VALUES OF E.S.R. IN FIVE GROUPS OF BLOOD DONORS

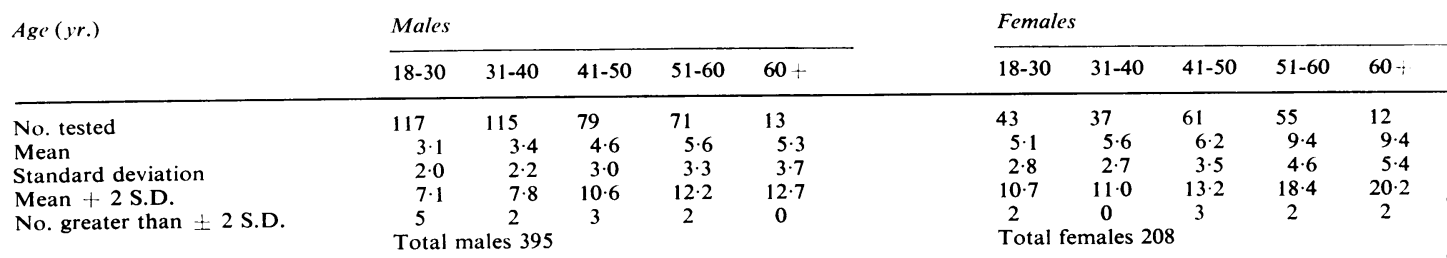




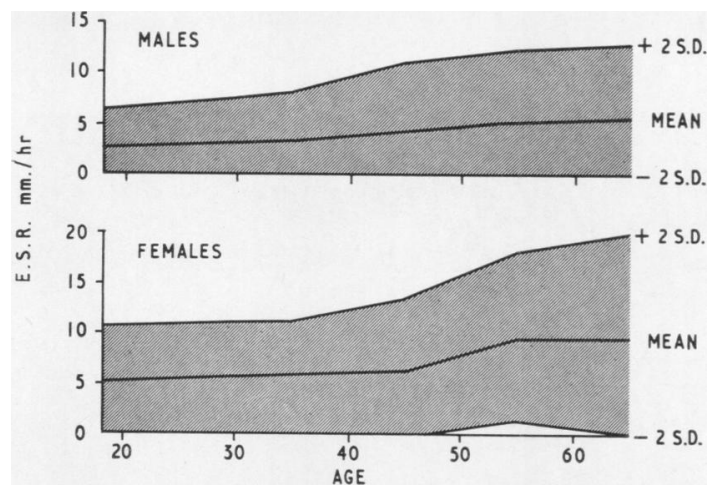

FIG. 1. Summary of the results for the combined groups.

deviations. Table I and Fig. 1 summarize the results for the combined groups of 395 males and 208 females. It may be seen that in males the mean E.S.R. rose from $3 \cdot 1 \mathrm{~mm}$. per hour at ages $18-30$ to $5 \cdot 3 \mathrm{~mm}$. at ages over 60 , and in females from 5.1 to $9.4 \mathrm{~mm}$. per hour. Simultaneously the size of the standard deviation increased. The distribution of readings was such that less than $5 \%$ of members exceeded the statistical level of significance of mean \pm 2 standard deviations in any group, except that of females above 60 where numbers were small. In all groups the values for mean +2 standard deviations exceeded the upper limits of those generally accepted as normal (Whitby and Britton, 1963). We conclude that there is evidence that the E.S.R. of normal individuals increases with age, and that the upper limit of 'normal' values given in standard textbooks is too low.

\section{DISCUSSION}

Various authors have expressed the opinion that the usually accepted range of normal values for the
E.S.R. is too narrow. Dawson (1960) considered that the range should be $0-10 \mathrm{~mm}$. per hour for males and 0-15 for females. Ansell and Bywaters (1958) stated that the value in normal adults did not exceed $20 \mathrm{~mm}$. per hour. Westergren's (1926) original normal values were $0-5 \mathrm{~mm}$. per hour for males and $0-10 \mathrm{~mm}$. for females, but he did not consider readings as raised until they exceeded $10 \mathrm{~mm}$. in men and $15-20 \mathrm{~mm}$. in women. Ansell and Bywaters (1958) and Olbrich (1948) noted that in people over 60 the normal E.S.R. is higher than that in younger age groups. It has always been difficult to be certain of the significance of borderline readings of the erythrocyte sedimenta-

TABLE II

UPPER LIMITS OF NORMAL (MEAN + 2 S.D.) IN WESTERGREN SEDIMENTATION RATE

\begin{tabular}{lcc}
$\begin{array}{l}\text { Age } \\
(y r .)\end{array}$ & $\begin{array}{l}\text { Male } \\
(\mathrm{mm} . \text { in one hour })\end{array}$ & $\begin{array}{l}\text { Female } \\
(\mathrm{mm} . \text { in one hour })\end{array}$ \\
\hline $18-30$ & 7 & 10 \\
$31-40$ & 8 & 11 \\
$41-50$ & 10 & 13 \\
$51-60$ & 12 & 18 \\
$60+$ & 13 & 20
\end{tabular}

tion rate. Our own results suggest that this can be more easily assessed if the subject's age is taken into account. Table II gives the figures (means +2 S.D.) which our survey indicates as the upper limits of normal for five age groups.

\section{REFERENCES}

Alexander, W. D. (1953). Brit. med. J., 1, 433.

Ansell, B., and Bywaters, E. G. L. (1958). Ibid., 1, 372.

Dawson, J. B. (1960). Ibid., 1, 1697.

Manley, R. W. (1957). J. clin. Path., 10, 354.

Olbrich, O. (1948). Edinb. med. J., 55, 100.

Westergren, A. (1926). Amer. Rev. Tuberc., 14, 94. Whitby, L. E. H., and Britton, C. J. C. (1963). Disorders of the Blood,
9th ed. Churchill, London. 